\title{
DISSERTAÇÕES DE MESTRADO E TESES DE DOUTORADO/2010
}

\author{
Universidade Federal do Rio de Janeiro \\ Centro de Filosofia e Ciências Humanas \\ Instituto de Psicologia \\ Programa de Pós-graduação em Teoria Psicanalítica
}

\section{DISSERTAÇÕES}

Título: Sintoma e satisfação em Freud Autora: Ana Beatriz Magalhães da Rosa Orientadoras: Giselle Falbo/Regina Herzog

Data de defesa: fev/2010

O presente trabalho visa situar a satisfação obtida através do sintoma, por meio da articulação dos conceitos contidos na primeira e segunda tópica freudiana, analisando a sua obra desde os momentos iniciais da construção teórica da satisfação no sintoma, situada nos limites do princípio do prazer, passando pelos seus questionamentos, em função dos entraves terapêuticos com que Freud se deparou, até o momento em que ele, muda de posição e lança uma nova luz sobre esta relação, concebendo uma satisfação que vai além dos limites do princípio do prazer, associada a compulsão à repetição e a pulsão de morte. Essa análise é realizada a partir de uma revisão bibliográfica dos textos do próprio Freud e de outros autores que se debruçaram sobre esse tema.
Título: Dor, prazer e desprazer na obra freudiana

Autora: André Félix de Sousa Orientadoras: Maria Isabel Fortes/ Regina Herzog Data de defesa: fev/2010

A dissertação investiga como o sujeito lida com o prazer, o desprazer e a dor partindo das primeiras investigações de Freud sobre o sintoma até a constituição do conceito de pulsão, através do qual a satisfação é definida como parcial. Condição que destaca a relação bastante particular do sujeito experimentar as sensações de prazer e desprazer como resultado de um único acontecimento. A pesquisa compreende as sensações de prazer e desprazer como pertencente ao registro da representação. E mais, procura demonstrar como o próprio aparelho psíquico, regido pelo princípio de desprazer/ prazer, constitui-se como um aparelho de representação, derivado da força pulsional. Num último momento, evidenciando a compreensão de Freud sobre a dor como invasão, transbordamento de energia no aparelho psíquico, vê-se que a dor situa-se no registro quantitativo, em oposição às sensações de prazer e desprazer. Assim, argumentamos que prazer e desprazer são formas pelas quais o aparelho psíquico, inscrito na ordem representacional, lida com a dor. 
Título: Experiência moral e responsabilidade: um estudo psicanalitico

Autor: Antonio Carlos Rabelo Dalbone Júnior

Orientadora: Angélica Bastos

Data de defesa: fev/2010

Esta dissertação realiza um exame acerca da experiência moral a que a clínica tem acesso através do conceito de supereu, investigando, em seguida, a noção de responsabilidade em psicanálise. A partir da introdução de das Ding, o trabalho aborda o vínculo fundamental entre lei e satisfação, qualificando a experiência moral como uma experiência de satisfação. Para tanto, examina-se o 'paradoxo da satisfação', apontando-se o componente pulsional no supereu. A partir de Lacan, investigase a moral kantiana e verifica-se que o imperativo categórico kantiano e a antimoral sadeana compartilham aspectos formais da lei, aspectos que a reflexão da psicanálise sobre a ética desvela ao isolar o gozo inerente à ação moral e o imperativo subjacente à ação libertina. Através da "Antígona" de Sófocles, a lei do desejo em psicanálise é trabalhada, destacandose a perda que lhe é intrínseca, índice da impossibilidade do gozo. Em seguida, discute-se a questão da responsabilidade em psicanálise, primeiramente por meio de um percurso na obra freudiana. Um diálogo com o direito é estabelecido, e o problema da responsabilidade é situado para além da estrutura subjetiva, precisamente em torno da relação do sujeito com seu gozo. Da discussão acerca da responsabilidade trágica, destaca-se o lugar fundamental da decisão subjetiva no tocante à responsabilidade em psicanálise. Conclui-se que o exame da responsabilidade não deve recair sobre o aspecto estrutural, aspecto que revela apenas as condições de resposta do sujeito, mas sim, sobre a lida do sujeito com seu gozo.

\section{Título: Inconsciente e experiência analitica}

Autor: Eduardo Ramalho Rotstein Orientadora: Angélica Bastos

Data de defesa: fev/2010

Esta dissertação versa sobre os fundamentos da psicanálise, notadamente, sobre a experiência em análise, tida pelos maiores representantes dessa disciplina - Freud e Lacan - como a principal fonte de seus conceitos e como meio de tratamento psíquico. Contudo, a procedência empírica da psicanálise é posta em dúvida tão logo se tem em conta que o objeto da investigação e prática analíticas é o inconsciente, algo que escapa a toda percepção sensível. Partindo da premissa de que há uma experiência em análise, damo-nos por tarefa investigar as relações que esta entretém com o inconsciente. O ponto de partida são os desenvolvimentos de Freud, o primeiro a identificar a experiência como um dos traços essenciais da psicanálise e a levantar a questão acerca da natureza empírica do inconsciente. Primeiramente, remontamos essa questão ao seu pressuposto: uma concepção de experiência nuançada, cujo sentido 'científico' prevalece sobre os sentidos 'etimológico' e 'clínico'. Em seguida, examinamos a solução que lhe dá o inventor da psicanálise a partir das discussões em torno do caráter especulativo da metapsicologia, de suas relações para com a metafísica, e da possibilidade de prova empírica em favor da existência de seu objeto. Por fim, apresentamos os desenvolvimentos de Lacan a respeito de nosso tema. As considerações 
sobre a peculiaridade da realidade psíquica e a ênfase posta sobre a fala na descrição do método analítico resultam, é verdade, numa concepção original de experiência analítica e de inconsciente, mas a reflexão lacaniana aproxima-se da de seu predecessor quanto às relações que por vezes estabelece entre esses dois conceitos. Ainda que distintas, as reflexões conduzidas pelos dois psicanalistas convergem, enfim, para o fundamento não empírico da experiência em análise.

\section{Título: Violência, guerra e politica segundo o pensamento freudiano Autora: Fernanda Passarelli Hamann Orientadora: Regina Herzog Data de defesa: fev/2010}

Este trabalho tem por objetivo pesquisar os modos como a violência é abordada no contexto do pensamento freudiano, especialmente em sua articulação com a guerra e a política. Primeiramente, procura-se apresentar as diversas modalidades de violência referidas pelo discurso freudiano. A seguir, realiza-se uma leitura dos textos de Freud a respeito da guerra, dos quais são extraídas e abordadas as principais menções a moções de violência. Finalmente, são lidos também textos de Freud a respeito da civilização, dos quais são destacadas e analisadas as principais menções a moções de violência envolvidas na política. A pesquisa conduz à formulação de três pontos conclusivos. O primeiro se refere a uma associação entre sadismo e guerra, e entre masoquismo e política. O segundo se resume pela assertiva de que a política pode ser entendida como o negativo da guerra. E o terceiro gira em torno de uma discussão sobre o porquê do pacifismo.
Título: $A$ estrutura do discurso do analista na linguagem

Autora: Julia Quaresma de Araújo Serpa Orientadora: Fernanda Costa-Moura Data de defesa: mar/2010

O presente trabalho tem como tema a relação da psicanálise com a linguagem e a construção do conceito "discurso do analista” na obra de Lacan. Veremos de que maneira o autor, ao retomar as concepções de Freud e tendo como foco a linguagem, pôde elaborar a sua teoria dos discursos. Da constituição do sujeito, uma vez que marcado pela incidência do significante, podemos extrair os quatro elementos presentes nos quatro discursos estabelecidos por Lacan, a saber: o próprio sujeito barrado (\$), o significante-mestre $\left(\mathrm{S}_{1}\right)$, o saber $\left(\mathrm{S}_{2}\right)$ e o objeto a. Considerando que a psicanálise é uma práxis, temos também como objetivo verificar os motivos pelos quais ela não pode se estabelecer como uma visão de mundo. Conclui-se que, ao endereçar sua fala ao Outro, o sujeito em análise não encontra um Mestre que possa solucionar sua divisão. Aí reside a diferença entre a psicanálise e os demais discursos ou laços sociais.

\section{Título: Um estudo sobre}

a neurose em Freud

Autora: Júlia dos Santos Moura

Orientadora: Anna Carolina Lo Bianco Data de defesa: fev/2010

O interesse de estudo na presente dissertação surge com a escuta regular da referência ao período da infância como algo de suma importância. Vemos, de saída, a família como uma organização significante que determina lugares para 
um sujeito, formando um corpo, um conjunto funcional destinado a se perpetuar. Entretanto, ela não configura tal panorama sem a determinação significante. A família é, portanto, uma modalidade de funcionamento significante. Vemos, com Freud, que a histeria decorre da alteração, de uma disfunção do aparelho sexual feminino. Ao longo da escrita e leitura de seus textos, a defesa ganha lugar no entendimento e na promoção de uma organização psíquica, quando observa que o que encontramos nas neuroses são representações excessivamente intensas. O aparelho se defende, então, de uma representação. Vemos o esboço do recalque e do sexual como elementos caros à psicanálise. Freud se detém primeiramente na teoria da sedução para aludir aos quadros neuróticos e só posteriormente o complexo de Édipo ganha relevância, junto com o recalque e a diferença sexual, agora já estabelecidos. O complexo de Édipo se interpõe como fenômeno central da primeira infância e de sua operação decorre que, após abandonar seus queridos objetos de amor, um sujeito, na melhor das hipóteses, isto é, enquanto neurótico, identifica-se como homem ou como mulher. Os quadros da neurose obsessiva e da histeria ganham consistência ao longo da elaboração freudiana. Entretanto, ao abrir mão desses objetos, parte da libido é subtraída da vida real, estabelecendo, na mesma medida, uma erótica. Chegamos à conclusão de que a família nos forma ao preço de uma falha fundante e fundamental. Partimos, com Melman, do sujeito como resto patológico proveniente de uma família enquanto lugar de circulação significante para chegarmos, ao final do trabalho, com Freud, à neurose como algo real que advém do campo sexual e que os funda, homem e mulher.
Título: As relações entre sintoma e cultura na psicanálise

Autor: Marcelo Reno Arbex

Orientador: Joel Birman

Data de defesa: fev/2010

O aparecimento de novos quadros sintomáticos na contemporaneidade que interrogam a prática psicanalítica e seus pressupostos, também traz a questão da causa de tais mudanças. Assim, diversos psicanalistas atualmente têm recorrido às diferenças culturais para explicar essa maior frequência, baseando-se na correlação entre sintoma e cultura que a psicanálise advoga. O objetivo desse trabalho é investigar como a psicanálise, através do estudo das neuroses, pode formular a correlação entre sintoma e contexto cultural e descobrir qual é a sua especificidade nesta abordagem. Inicialmente, exporemos a relação feita entre os novos sintomas e a cultura contemporânea, para demonstrar a pertinência do tema. Em seguida, pretendemos retornar à criação da psicanálise para expor como em sua concepção inicial de sintoma já estava incluída a dimensão cultural. A partir daí, seguiremos o desenvolvimento do conceito de sintoma na teoria psicanalítica, ao lado das hipóteses sobre cultura realizadas por Freud. Pretendemos demonstrar como o contexto cultural está implícita no aparelho psíquico formulado por Freud e no sintoma. A concepção que será traçada irá contra a divisão entre um polo individual, tratado no sintoma e um polo cultural, como um objeto de estudo separado da psicanálise pura, levando em consideração a indivisibilidade dos dois campos desde o início da teoria psicanalítica. 
Título: Adolescência: segundo tempo da constituição do sujeito

Autora: Marisa Helena Cytryn Solberg

Orientadora: Fernanda Costa-Moura

Data de defesa: fev/2010

A presente pesquisa se caracteriza como um estudo teórico-clínico sobre o advento do sujeito na adolescência. Compreende que a operação da castração se deu na infância e que, com a puberdade, o jovem é convocado a se submeter novamente a essa operação para tomar lugar no desejo sexual. Desencadeando a "crise psíquica" que conhecemos como adolescência: um segundo tempo, que implica a assunção da castração sustentada não mais pelos ideais, mas em ato - por sua própria conta e risco, no exato momento em que o jovem descobre que o sexual é falho, é perda. A partir destas considerações busca-se discutir de que modo o encontro com o sexual convoca o adolescente a se responsabilizar pelos seus atos. Concluise que o que é próprio da adolescência é justamente o advento do sujeito que, tendo enfim o ato sexual a sua disposição, deve, doravante, responsabilizar-se pelo sexual atravessado pela castração. Arcando em nome próprio com o ônus (e o bônus) do desejo que daí resulta. A reflexão clínica, por sua vez, permite observar que este advento do sujeito na adolescência depende estritamente de um passo ético que o jovem possa vir a dar, ou não. Não há nada que possa antecipar ou garantir esse efeito de segundo tempo para o sujeito.
Título: Dor física crônica: uma reflexão psicanalítica

Autora: Patrícia Paraboni

Orientadora: Marta Rezende Cardoso

Data de defesa: fev/2010

O principal objetivo deste trabalho é investigar a origem psicogênica no fenômeno doloroso crônico quando este não apresenta etiologia de base orgânica. Procuramos mostrar o quanto tal fenômeno se aproxima da melancolia, seja pelo aspecto econômico, seja pela impossibilidade, presente em tais pacientes, quanto a realizar o trabalho de luto. Ambos os aspectos parecem determinantes na dor física crônica psicogênica.

$\mathrm{Na}$ investigação de nossas hipóteses adentramos, primeiramente, no campo do traumático, pois acreditamos que ele esteja na base desse tipo de fenômeno doloroso. A impossibilidade de representar psiquicamente a excitação pulsional força o aparelho a encontrar outros meios, mais arcaicos, de defesa. Tal caso é o que ocorre na dor física crônica, onde a convocação do corpo parece funcionar, paradoxalmente, como forma extrema de proteger o psiquismo dos efeitos devastadores do traumático. A regressão a um modo de funcionamento no qual o corporal tornase predominante acaba por engendrar uma economia psíquica singular e, ao mesmo tempo, uma dependência ao objeto-dor como garantia de existência subjetiva. As queixas de dores físicas, proferidas de modo insistente por esses pacientes, nos levaram a empreender investigação acerca das relações eu-outro. A impossibilidade de realização do trabalho do luto, devida à força do traumático, impede o paciente de abdicar de suas dores físicas. O aspecto que acreditamos merecer destaque na dimensão da queixa é o papel de apelo ao 
outro. Entendemos que na queixa há um endereçamento ao outro, ou seja, uma demanda de legitimação da existência de tais dores.

Título: Sintoma histérico: sujeito e corpo em seu retorno do exílio Autora: Renata Vianna Gomide Orientadora: Ana Beatriz Freire Data de defesa: fev/2010

A revolução científica do século XVII, operada por Galileu, Kepler e Descartes, excluiu o sujeito de suas considerações, em uma atitude que Lacan descreve como um "nada querer saber" frente às questões propriamente subjetivas. Além dessa rejeição do sujeito, ocorreu, no discurso científico, uma outra rejeição, a do corpo. Através do cogito (penso, logo sou), Descartes reduz o ser do sujeito ao pensamento, relegando assim o corpo à extensão e promovendo o exílio deste. Ao iniciar seus estudos em psicanálise, Freud se depara com o corpo da histérica, um corpo irredutível ao saber médico, consistindo em uma via de manifestação do discurso inconsciente. Apostando então nesta nova forma de pensar o corpo, Freud promove o retorno do corpo de seu exílio. Além disso, ao postular a existência de pensamentos inconscientes, Freud acolhe também o sujeito que a ciência havia rejeitado. Neste sentido, nosso objetivo é demonstrar que com o sintoma histérico a Psicanálise recolhe os dois excluídos pela ciência: o sujeito e seu corpo. Desta forma, ao tratar de questões que a ciência rejeita, a psicanálise se constitui como um campo de problemas único, distinto da ciência.

\section{TESES}

Título: Da perversão à sublimação:

algumas estratégias das artes visuais para a criação de lugares de subjetivação e presença de obra nas bordas do corpo e do feminino Autora: Alessandra Monachesi Ribeiro Orientador: Joel Birman

Data de defesa: jul/2010

A presente tese busca perscrutar as possibilidades de subjetivação para o homem contemporâneo a partir de sua localização no lugar de ausência de obra inaugurado, no século XVII, pela loucura oposta como desrazão e expandida para o campo das subjetividades, através de sua patologização e consequente medicalização, ao longo desse tempo e até nossos dias. Do lugar da ausência de obra, em que a subjetivação mal tem condições de se fazer, submetidos que estamos ao saber/poder disciplinar que recai sobre nossos corpos, buscando dominá-los e torná-los servis, a possibilidade que surge é de que o sujeito advenha ali mesmo, dessa condição de ausência de obra, nas bordas, no mesmo campo antes consagrado à loucura. Recorrendo às artes visuais, e especialmente às artes visuais contemporâneas a partir das obras de Nazareth Pacheco, Cindy Sherman e Marina Abramovic, temos que o domínio das artes - quase um lugar clichê para a existência de obra - sustenta também essa tensão entre obra e sua desaparição nos mostrando que, se há subjetivação possível, ela não pode se fazer senão nas bordas. Por meio dos trabalhos de tais artistas, temos que tais bordas são aquelas do corpo e do feminino, lugares de fronteira tanto para o campo da arte quanto para o campo psicanalítico, de onde o sujeito pode partir em um proces- 
so de subjetivação que, novamente com o auxílio das artistas e daquilo que elas nos indicam através de seus temas e das formas de composição de suas obras, traça um percurso de um lugar cristalizado, aprisionado em uma condição perversa, rumo ao restabelecimento da possibilidade de movimento, trazido pela ideia de sublimação enquanto transgressão e profanação.

\section{Título: $\boldsymbol{A}$ drogadição}

\section{na estrutura neurótica}

Autor: Alexandre Bakx Balbi

Orientadora: Anna Carolina Lo Bianco

Data de defesa: set/2010

A presente tese de doutorado dirige-se a uma questão clínica que ganha particular relevância na atualidade: a drogadição. Considera a referida afecção tendo em vista a estrutura neurótica, uma vez que, recorrendo à perspectiva da psicanálise, a mesma não pode ser vista como uma estrutura equivalente à própria neurose, à psicose ou à perversão. Toma, portanto a drogadição na neurose, articulando a clínica aos conceitos analíticos, especialmente os de compulsão, gozo, supereu, falta e falo. Parte da hipótese de que quando uma drogadição se instala verificam-se mudanças significativas na neurose. Dentre elas a suspensão da existência do sujeito cuja consequência leva a uma compulsão incessante. Esta suspensão é acompanhada pela evitação pungente do encontro do sujeito com a falta.

A falta é fundamental para o sujeito tanto no que concerne ao desejo, quanto na possibilidade de seu gozo. Estando a falta tamponada pela droga, acaba-se necessitando, se o sujeito escolhe não se haver com ela, de uma dose a mais, depois outra e outra, até o ponto em que a falta vem a se tornar insuportável para ele. Verifica-se neste ponto a instalação de uma drogadição. Fica-se aí a mercê de um pêndulo entre um gozo narcísico e unificante da droga e um outro mortífero, puro desamparo pela ausência desta. Aqui verificamos um mandamento de gozo, comandado pelo supereu, que exige sempre um gozo a mais, sem parada, sem fim.

Concluímos então que apenas a escolha pelo desejo, pelo transitório, uma escolha pela ética que norteia a Psicanálise - a ética do desejo - é capaz de produzir uma falência, um ponto de basta neste furor drogadito que exige sempre uma dose a mais, um gozo a mais.

Título: Inibição, sintoma e angústia: o corpo nas neuroses

Autora: Alinne Nogueira Silva Coppus Orientadora: Angélica Bastos Data de defesa: jul/2010

O presente trabalho aborda a problemática do corpo nas neuroses com base na experiência psicanalítica. A tese sustenta a ideia de que o corpo se faz presente nos três registros -imaginário, simbólico e real-e se manifesta no campo da neurose como inibição, sintoma e angústia. A partir do percurso realizado por Freud e Lacan em relação a essa tríade, circunscreve-se um campo de pesquisa no qual se localizam os impasses do sujeito em relação ao corpo no campo da neurose.

A fim de atingir esse objetivo, retomase o início da psicanálise com a histeria, exploram-se os principais conceitos psicanalíticos que tangem o corpo, como a pulsão, a angústia, o narcisismo e o eu. Definido como uma imagem transpassada pelo significante e animada pela libido a 
partir da extração do objeto a, destacamse as condições necessárias para que o sujeito construa um corpo. Articulado aos três registros, o corpo é um objeto de estudo psicanalítico que acompanha todo o ensino de Lacan, um instrumento que fornece consistência ao sujeito, materializa seu desejo e localiza seu gozo.

Retira-se da clínica da neurose sintomas que ilustram, de maneira clara e instigante, os impasses que 'ter um corpo' implica para o sujeito. Com a anorexia e a bulimia, demonstra-se o papel fundamental que a imagem possui para o sujeito. Além disso, os diversos modos de apresentação do corpo na neurose obsessiva permitem o questionamento da clássica separação entre histeria e corpo, de um lado, e obsessão e pensamento, de outro.

Constata-se que a angústia, a inibição e o sintoma servem de bússola ao analista no que diz respeito aos pontos que norteiam a neurose - o desejo e o gozo - e possuem como elemento comum o fato de envolverem necessariamente o corpo para se manifestarem. Por fim, o corpo é situado na topologia do nó borromeano, o que permite demarcar a angústia, a inibição e o sintoma nos registros do real, do simbólico e do imaginário.

\section{Título: Drogadicção na juventude contemporânea: a "intoxicação" pelo outro}

Autora: Bianca Bergamo de Andrade Savietto

Orientadora: Marta Rezende Cardoso Data de defesa: fev/2010

Nosso objetivo é investigar o fenômeno da drogadicção na juventude contemporânea, enfocando a confluência dessa problemática com elementos próprios à família na qual os jovens se desenvolvem. Analisamos, privilegiadamente, aspectos intrínsecos ao âmbito da família atual, que constituem entraves aos processos de subjetivação dos jovens, à sua caminhada rumo à independência, e concorrem para o estabelecimento de adicção às drogas. Nas famílias dos jovens toxicômanos da atualidade parece haver persistência de relações predominantemente narcísicas, implicando confusão de lugares.

Examinamos especificidades do funcionamento psíquico do sujeito drogadicto, como a tendência radical à descarga, e falta de mobilização de forças para verdadeiro trabalho psíquico. Tal dinâmica está dominada pelo registro além do princípio de prazer, sob as forças de descarga e do desligamento, evidenciadas na compulsão à repetição. Sendo compulsivo, o recurso ao objeto-droga indica envolvimento de tipo peculiar de dependência - dependência patológica, contrária à progressiva diferenciação entre sujeito e objeto, e entre instâncias psíquicas.

A evacuação da excitação psíquica é buscada pelo compulsivo abuso de substâncias tóxicas. Porém, a tendência à descarga total é freada pela repetitiva utilização dessas mesmas substâncias. A busca de onipotência e satisfação absoluta revela dependência e desamparo, e tentativa paradoxal de escapar. Também exploramos tais paradoxos, dando relevo à dimensão de automedicação, de "autotratamento" da drogadicção. O sujeito toxicômano procura marcantemente abrigar-se no registro da onipotência, para não se esvair no nada absoluto da descarga radical. Entretanto, quanto mais o eu tenta se afirmar num "fechamento narcísico", mais se faz, paradoxalmente, desaparecer. 
Título: $\boldsymbol{A}$ clínica psicanalitica do ato infracional - os impasses da sexuação na adolescência Autora: Christiane da Mota Zeitoune Orientadora: Tânia Coelho dos Santos Data de defesa: ago/2010

Esta tese discute, a partir do atendimento a adolescentes autores de ato infracional e em cumprimento de medida socioeducativa, a possibilidade de fazer operar o discurso psicanalítico nesse campo onde predomina o discurso jurídico, correcional e repressivo. Como promover uma mudança subjetiva nesses jovens capturados pela pobreza e pela fragilidade dos laços sociais? A que esse ato infracional vem responder? Os atendimentos ao adolescente e às suas famílias demonstram que o envolvimento desses jovens com os atos infracionais não se deve à pobreza, ao desemprego ou à necessidade de dinheiro, mas apontam para o impasse do sujeito com a castração. O afrouxamento dos laços familiares e o empuxo ao consumo, que caracteriza a nossa civilização contemporânea, fazem com que os adolescentes tenham mais dificuldades de subjetivar a lei, inscrever a castração e, consequentemente, se embaracem ao ter que assumir uma posição sexuada. Percorremos os textos de Freud e Lacan para demonstrar que o envolvimento do adolescente no ato infracional evidencia o embaraço que o sujeito experimenta ao ter que tomar posse do atributo fálico. Na relação com o Outro, no lugar de fazer um sintoma, o adolescente faz um ato. Não pensa, atua. O ato é uma resposta que exclui o sujeito, mas que produz consequências. É a partir da consequência do ato que o analista irá operar, buscando produzir uma resposta subjetiva. Para isto, é necessário elevar o ato, tipificado como crime, à categoria da responsabilidade e da verdade do sujeito. Através do atendimento individual ao adolescente em cumprimento de medida socioeducativa e da prática da "Conversação” com as famílias, com os profissionais e com os adolescentes encontramos formas de dar tratamento ao gozo e estratégias para dar conta do mal-estar que se apresenta neste trabalho.

\section{Título: Antígona e o fundamento trágico da ética da psicanálise Autora: Ingrid de Mello Vorsatz Orientadora: Fernanda Costa-Moura Data de defesa: fev/2010}

A tese investiga em que medida o ethos trágico, ao iluminar a relação do sujeito ao seu ato, pode contribuir para a fundamentação da ética da psicanálise. Uma ética que parte da exclusão da possibilidade de conformidade a um bem - assim como a tragédia antiga - e coloca em questão não mais os desígnios insondáveis dos deuses ou a inexorabilidade do destino, mas sim a relação do ato do sujeito ao desejo que o constitui. Uma relação que se funda em perda, em descontinuidade com a cadeia ou a ordem causal que antecede e engendra o sujeito, fazendo ressaltar a dimensão objetal deste sujeito paradoxal. Por meio da discussão que contempla a decisão inarredável da heroína trágica Antígona de Sófocles - a qual apresenta avant la lettre e no real da cena a tensão irreconciliável entre determinação e responsabilidade constitutiva do sujeito do inconsciente -, procura-se delimitar a essência da ação trágica como consistindo no ato. Ocorrência que, se exclui a dimensão de mestria, implica, não obstante, em responsabilidade plena para o sujeito. 
Título: Inconsciente

e responsabilidade

Autor: Jorge de Figueiredo Forbes

Orientadora: Tânia Coelho dos Santos

Data de defesa: set/2010

Esta tese argumenta em favor de uma mudança necessária na clínica psicanalítica: de uma psicanálise praticada no século XX para uma nova do século XXI. Para tanto se baseia na orientação lacaniana, da passagem da primeira para a segunda clínica de Lacan. A primeira clínica, ou a do significante, que privilegia o registro do Simbólico, foi a que dominou por muito tempo a psicanálise, sendo adequada a um mundo onde o laço social se estruturava verticalmente, destacando o sentido do Pai. A segunda clínica surgiu da necessidade da psicanálise responder a novos sofrimentos proporcionados por um laço social horizontalizado, efeito da globalização. Se na primeira o Complexo de Édipo era soberano, na segunda, a psicanálise vai além do Édipo, além do sentido do Pai, pondo o Real no lugar privilegiado, anteriormente ocupado pelo Simbólico. Ao privilegiar o Real sobre o Simbólico e o Imaginário, a prática clínica muda de uma posição de "dar um sentido a mais", consagrado nas interpretações das formações do inconsciente recalcado, para o seu avesso: um limite ao sentido, um basta à ideia de que haveria sempre algo mais a ser explicado. É esse aspecto que se condensa no título da tese: Inconsciente e Responsabilidade, pois, contrariamente ao que costumeiramente se pensa, somos sim responsáveis pelo acaso e pela surpresa. Casos clínicos são relatados para evidenciar essa passagem que em Lacan é dita como a de um sintoma a ser decifrado, a um sintoma duro, indecifrável, identidade da pessoa, detectável no seu ponto de vergonha/honra essencial. 